Article

\title{
Efficient Production of N-Butyl Levulinate Fuel Additive from Levulinic Acid Using Amorphous Carbon Enriched with Oxygenated Groups
}

\author{
Jinfan Yang ${ }^{1, *}$, Guangyi $\mathrm{Li}^{2}$, Lulu Zhang ${ }^{1}$ and Sufeng Zhang ${ }^{1, *}$ \\ 1 Key Laboratory of China National Light Industry, College of Bioresources Chemical and Materials \\ Engineering, Shaanxi University of Science \& Technology, Xi'an 710021, China; lucy.20062008@163.com \\ 2 Dalian Institute of Chemical Physics, Chinese Academy of Sciences, Dalian 116023, China; \\ lgy2010@dicp.ac.cn \\ * Correspondence: yangjinfan@sust.edu.cn (J.Y.); sufengzhang@sust.edu.cn (S.Z.); \\ Tel.: +86-029-8616-8575 (J.Y.); +86-029-8616-8238 (S.Z.)
}

Received: 7 December 2017; Accepted: 5 January 2018; Published: 9 January 2018

\begin{abstract}
The aim of this study was to develop an effective carbonaceous solid acid for synthesizing green fuel additive through esterification of lignocellulose-derived levulinic acid (LA) and n-butanol. Two different sulfonated carbons were prepared from glucose-derived amorphous carbon (GC400) and commercial active carbon (AC400). They were contrastively studied by a series of characterizations $\left(\mathrm{N}_{2}\right.$ adsorption, $\mathrm{X}$-ray diffraction, elemental analysis, transmission electron microscopy, Fourier transform infrared spectroscopy and $\mathrm{NH}_{3}$ temperature programmed desorption). The results indicated that GC400 possessed stronger acidity and higher $-\mathrm{SO}_{3} \mathrm{H}$ density than $\mathrm{AC} 400$, and the amorphous structure qualified GC400 for good swelling capacity in the reaction solution. Assessment experiments showed that GC400 displayed remarkably higher catalytic efficiency than AC400 and other typical solid acids (HZSM-5, H $\beta$, Amberlyst-15 and Nafion-212 resin). Up to $90.5 \%$ conversion of LA and $100 \%$ selectivity of n-butyl levulinate could be obtained on GC400 under the optimal reaction conditions. The sulfonated carbon retained $92 \%$ of its original catalytic activity even after five cycles.
\end{abstract}

Keywords: solid acid; sulfonated carbon; levulinic acid; n-butyl levulinate; fuel additive

\section{Introduction}

In recent years, the foreseeable depletion of fossil energy and growing environmental concerns have drawn tremendous attention towards the conversion of renewable biomass into fuels [1-3] and fine chemicals $[4,5]$. Lignocellulose is the major component of agricultural waste and forest residues. Levulinic acid (LA) derived from the deconstruction of lignocellulose is a versatile platform chemical, and it has been highlighted by the United States Department of Energy as a promising building block for chemistry in 2004 and 2010 [6]. Among the downstream derivativities of LA, alkyl levulinates are of particular interest due to their extensive applications in the flavoring, solvent and plasticizer sectors [4,7]. Moreover, the low toxicity, high lubricity, stable flash point and moderate flow property make alkyl levulinates suitable additives for gasoline and diesel fuels [8].

Generally, alkyl levulinates are obtained by esterification of LA with alcohols using mineral acids, which lead to some difficulties in catalyst recycling, product separation and environmental protection. Substitution of homogeneous catalysts by heterogeneous catalysts is highly desirable to avoid handling corrosion and environmental problems. As far as we know, most studies were focused on the synthesis of ethyl levulinate (EL). For this purpose, various solid acid catalysts have been developed, including supported heteropolyacid [9,10], zeolites [11,12], sulfonated metal oxides [13] 
and silicas [14], sulfonated carbon nanotubes [15], Starbon ${ }^{\circledR}$ mesoporous carbon [16], and hybrid catalysts [17].

Comparatively, the potential of butyl levulinate (BL) has been left unexploited. It is worth noting that BL has been proved to be more promising than EL as a fuel additive [18,19]. They both could improve lubricity, conductivity and reduce particulate emissions in diesel blending. The esters displayed 25\% (BL) and 31\% (EL) less energy per volume than conventional diesel fuel. It is already an upgrading on bioethanol blends. On the other hand, BL has an evidently lower solubility in water $(1.3 \mathrm{wt} \%)$ than EL (15.6 wt \%). In diesel blends containing 20\% $(v / v)$ alkyl levulinate, EL was found to form a separate liquid phase from diesel at $283 \mathrm{~K}$, while BL remained constant miscibility in diesel even at the diesel cloud point (247 K) [20].

Nowadays, the application of acetone-butanol-ethanol fermentation technology to lignocellulose makes bio-butanol (n-butanol) become an inexpensive platform chemical to produce BL. However, the literature on the synthesis of BL via the esterification of LA are sparse. Several types of solid acids such as supported montmorillonite [21], zeolites [22,23], metal-organic frameworks [24], Al-MCM-41 [25], ion-exchange resins [26,27], graphene oxide [28] and immobilized lipase [29] have been utilized in the esterification of LA with n-butanol. Surprisingly, the catalysis with amorphous carbon materials to produce BL has not been explored before. The amorphous carbon obtained by incomplete carbonization of carbohydrate is a kind of soft carbon possessing polycyclic aromatic carbon sheets in a three-dimensional $\mathrm{sp}^{3}$-bonded structure [30,31]. After sulfonation, this amorphous carbon could generate a stable solid acid catalyst with abundant sulfonic sites, which has been reported to effectively catalyze the esterification of fatty acids to produce biodiesel [32-34]. So far, there has been no report about its utilization in esterification of LA to produce fuel additives.

In this work, two different sulfonated carbons obtained from glucose-derived amorphous carbon and conventional active carbon were prepared and evaluated their catalytic performance in the esterification of LA with n-butanol. Both carbon materials were characterized by $\mathrm{N}_{2}$ adsorption, X-ray diffraction (XRD), CHNS elemental analysis, Fourier-transform infrared spectra (FT-IR), high-resolution transmission electron microscopy (HRTEM), and $\mathrm{NH}_{3}$ temperature programmed desorption $\left(\mathrm{NH}_{3}-\mathrm{TPD}\right)$. The relationship between the catalytic performance and the physicochemical properties of carbon materials were discussed. Moreover, different experimental parameters, such as reaction temperature, reaction time, molar ratio of reactants, catalyst loading, and cycle times were optimized over sulfonated glucose-derived carbon.

\section{Results and Discussion}

\subsection{Catalyst Characterizations}

Figure 1 illustrates the XRD patterns of two sulfonated carbon materials. GC400 exhibited a weak and broad carbon (002) diffraction peak at $10-30^{\circ}$, which was attributed to amorphous carbon composed of aromatic carbon sheets oriented in a considerably random fashion [31]. This indicated that the sample was comprised of a high content of non-graphitic carbon structure. For an AC400 sample, a sharp diffraction peak at $26.1^{\circ}$ and a definitive carbon (101) diffraction peak at $40-50^{\circ}$ both demonstrated the formation of graphite structure in the active carbon [35]. The XRD results indicated that AC400 was more carbonized than GC400 and possessed larger carbon sheets. The amorphous structure of GC400 was further confirmed by HRTEM images (see Figure S1), as no evident graphene sheets were observed, while the image of AC400 clearly revealed the existence of curved graphene sheets that were randomly distributed. 


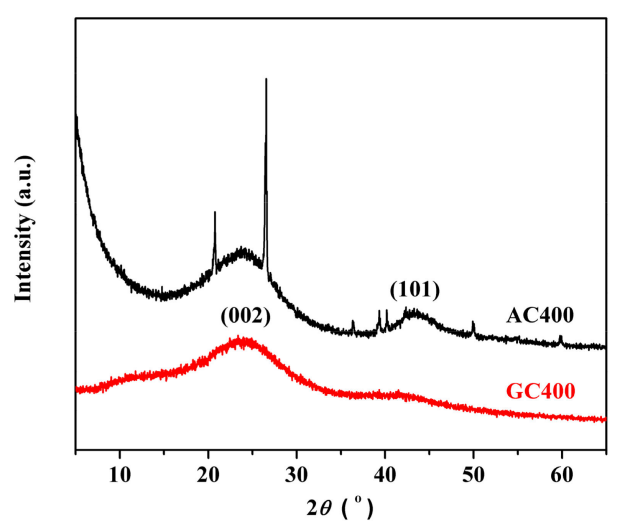

Figure 1. XRD patterns of two sulfonated carbon materials.

According to the results of CHNS elemental analysis shown in Table 1, GC400 had a lower carbon content and a higher hydrogen content than $\mathrm{AC} 400$, indicating the incomplete carbonization of glucose at $673 \mathrm{~K}$. In addition, the sulfur content of GC400 was remarkably higher than that of AC400. Since all the sulfur atoms have been proved to be existing as $-\mathrm{SO}_{3} \mathrm{H}$ groups [32], the $-\mathrm{SO}_{3} \mathrm{H}$ density of $\mathrm{GC} 400$ and AC400 were calculated to be $0.66 \mathrm{mmol} \cdot \mathrm{g}^{-1}$ and $0.2 \mathrm{mmol} \cdot \mathrm{g}^{-1}$, respectively. The higher $-\mathrm{SO}_{3} \mathrm{H}$ density of GC400 can be rationalized by its small non-graphitic carbon sheets that have more access to bind with $-\mathrm{SO}_{3} \mathrm{H}$ groups, as $-\mathrm{SO}_{3} \mathrm{H}$ groups can be only attached onto the edge of carbon sheets [31].

Table 1. The results of CHNS elemental analysis and surface areas.

\begin{tabular}{cccccc}
\hline \multirow{2}{*}{ Catalyst } & \multicolumn{4}{c}{ Elemental Composition $(\mathbf{w t} \%)$} & \multirow{2}{*}{$\mathbf{S}_{\text {BET }}\left(\mathbf{m}^{\mathbf{2}} \cdot \mathbf{g}^{\mathbf{- 1}}\right)$} \\
\cline { 2 - 5 } & $\mathbf{C}$ & $\mathbf{H}$ & $\mathbf{N}$ & $\mathbf{S}$ & \\
\hline GC400 & 57.76 & 2.33 & 0.13 & 2.13 & 2 \\
AC400 & 73.48 & 0.76 & 0.53 & 0.65 & 708 \\
\hline
\end{tabular}

Despite having high $-\mathrm{SO}_{3} \mathrm{H}$ density, GC400 had a rather small specific surface area $\left(2 \mathrm{~m}^{2} \cdot \mathrm{g}^{-1}\right.$, see Table 1), which was comparable to those reported in the literature [31,32]. It indicated most $-\mathrm{SO}_{3} \mathrm{H}$ groups were in the bulk structure, as opposed to on the outermost surface. Otherwise, there would have been an unreasonable number of $S$ atoms per unit surface area. The small surface area of GC400 did not necessarily imply limited access to active sites in the esterification. Figure S2 shows the behaviour of GC400 and AC400 in n-butanol. It is surprising to find the volume of GC400 increased by approximately 1.5 times while there was barely a change in AC400 volume. This phenomenon indicated that GC400 possessed swelling capacity to incorporate reactants into the $-\mathrm{SO}_{3} \mathrm{H}$ sites located in the bulk phase. The swelling capacity is originated from the small and flexible aromatic carbon sheets in amorphous structure [31]. In contrast, the flexibility of carbon sheets in AC400 decreased due to the higher graphitization, leading to the poor swelling capacity in reaction solution. The total acid densities of two carbonaceous materials were determined by two different methods $\left(\mathrm{NH}_{3}\right.$ adsorption and titration). The results were shown in Table S1. As we can see, the total acid densities of AC400 obtained by two methods were basically the same $\left(0.44 \mathrm{vs} .0 .46 \mathrm{mmol} \cdot \mathrm{g}^{-1}\right)$. However, the $\mathrm{NH}_{3}$ adsorption of GC400 resins resulted in a prediction of less than $10.9 \%$ of the real acid site density ( 1.1 vs. $1.22 \mathrm{mmol} \cdot \mathrm{g}^{-1}$ ). This gap can be explained by the acid site accessibility in swollen GC400 being of more relevance than accessibility in the dry sample. On the other hand, the total acid densities of two carbonaceous materials were both higher than their $-\mathrm{SO}_{3} \mathrm{H}$ densities. The reason can be attributed to a certain amount of $-\mathrm{COOH}$ and phenolic - $\mathrm{OH}$ groups presenting in the two catalysts, which agrees with the following FT-IR results. It also can be seen from Table S1 that AC400 possessed a remarkably lower amount of $-\mathrm{COOH}$ and $-\mathrm{OH}$ groups than GC400, and the deficiency of these oxygenated groups 
on the carbon surface of AC400 is supposed to decrease its interaction ability with polar compounds in reaction mixture.

The IR spectra of two sulfonated carbon catalysts are depicted in Figure 2. As for GC400 catalyst, the bands at $1034 \mathrm{~cm}^{-1}$ and $1172 \mathrm{~cm}^{-1}$ were ascribed to the $\mathrm{S}=\mathrm{O}$ symmetric and asymmetric stretching mode, providing the presence of $-\mathrm{SO}_{3} \mathrm{H}$ groups. The vibration bands at $1400 \mathrm{~cm}^{-1}$ and $1602 \mathrm{~cm}^{-1}$ were attributed to the aromatic $\mathrm{C}=\mathrm{C}$ stretching mode, suggesting the existence of polycyclic aromatic rings, which were formed from the incomplete carbonization of the glucose substance [36]. Meanwhile, the band at $1706 \mathrm{~cm}^{-1}$ was related to the $\mathrm{C}=\mathrm{O}$ stretching of the $-\mathrm{COOH}$ group. The bands in the range of $3000-3400 \mathrm{~cm}^{-1}$ were related to the $\mathrm{O}-\mathrm{H}$ stretching of the $-\mathrm{COOH}$ and phenolic $-\mathrm{OH}$ groups. Therefore, the Brønsted acid sites $\left(-\mathrm{SO}_{3} \mathrm{H}\right.$ and $\left.-\mathrm{COOH}\right)$ and almost neutral phenolic $-\mathrm{OH}$ groups were confirmed to be attached onto the aromatic carbon structure of GC400. This is distinct from conventional solid acids with single functional groups. On the other hand, the weak bands at $1172 \mathrm{~cm}^{-1}$, $1706 \mathrm{~cm}^{-1}$ and $3365 \mathrm{~cm}^{-1}$ on AC400 revealed its deficiency of $-\mathrm{SO}_{3} \mathrm{H},-\mathrm{COOH}$ and $-\mathrm{OH}$ groups.

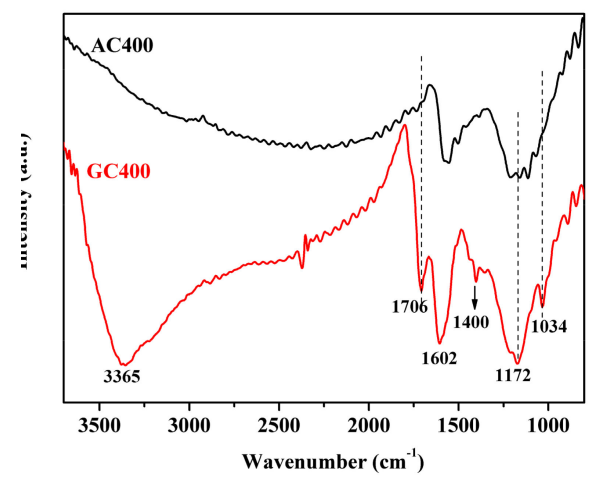

Figure 2. FT-IR results of two sulfonated carbon materials.

The distribution of acid strength on carbon materials is shown in Figure 3. Two broad desorption peaks ranging from 400 to $700 \mathrm{~K}$ and 800 to $1000 \mathrm{~K}$ were observed on GC400. The former peak indicated the presence of weak acid sites due to interaction of $\mathrm{NH}_{3}$ with incompletely formed carbon sheets and -COOH groups [37]. The latter peak maximized at $950 \mathrm{~K}$ was ascribed to the presence of strong acid sites due to desorption of $-\mathrm{SO}_{3} \mathrm{H}$ groups [37]. The $\mathrm{NH}_{3}$-TPD result of unsulfonated GC400 further proved the above discussion (see Figure S3). However, only one desorption peak ranging from 400 to $570 \mathrm{~K}$ was detected on $\mathrm{AC} 400$, the missing desorption peaks at elevated temperature revealed its weak acid strength owing to the deficiency of $-\mathrm{SO}_{3} \mathrm{H}$ groups. The result was in accordance with the FT-IR and elemental analysis.

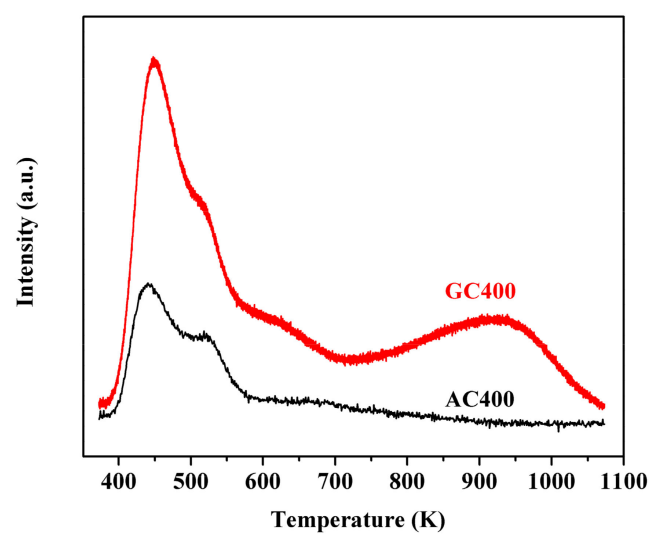

Figure 3. $\mathrm{NH}_{3}$-TPD results of two sulfonated carbon materials. 


\subsection{Esterification Activity over Two Sulfonated Carbon Materials}

Two sulfonated carbons were comparatively evaluated in the esterification of LA with n-butanol (Scheme 1) at $373 \mathrm{~K}$ for $4 \mathrm{~h}$, n-butanol to LA molar ratio of 5:1, and catalyst loading of $10 \mathrm{wt} \%$ with respect to LA. In all cases, the selectivity of BL remained 100\%. By-products like ethers coming from the intermolecular dehydration of alcohols were not observed under the moderate reaction conditions (see Figure S4). A blank experiment with 5.2\% conversion of LA indicated that LA could catalyze the reaction as a weak acid catalyst [13]. Figure 4 shows that both sulfonated carbons exhibited a certain extent of catalytic activity, while a significantly higher reaction rate and LA conversion were obtained on GC400. The conversion could be consolidated through prolonging the reaction time within $4 \mathrm{~h}$. After that, the promotion effect was weakened due to the equilibrium limitation. Finally, $90.5 \%$ conversion of LA on GC400 and 15.6\% conversion of LA on AC400 were obtained. Therefore, the reaction time of $4 \mathrm{~h}$ was observed to be an optimum. The catalytic performances of two carbonaceous materials were quantified as turnover frequency (TOF) based on the amount of $-\mathrm{SO}_{3} \mathrm{H}$ sites and LA conversion at the initial stage. The calculated TOF value was $23.3 \mathrm{~h}^{-1}$ on AC400 and $95.8 \mathrm{~h}^{-1}$ on GC400.

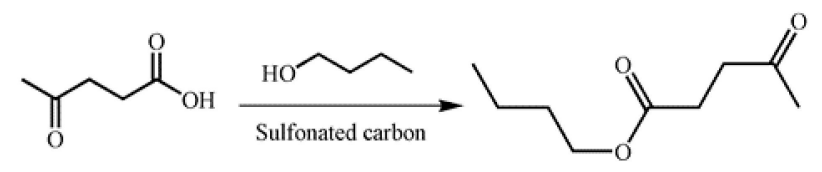

Scheme 1. Sulfonated carbon catalyzed esterification of LA.

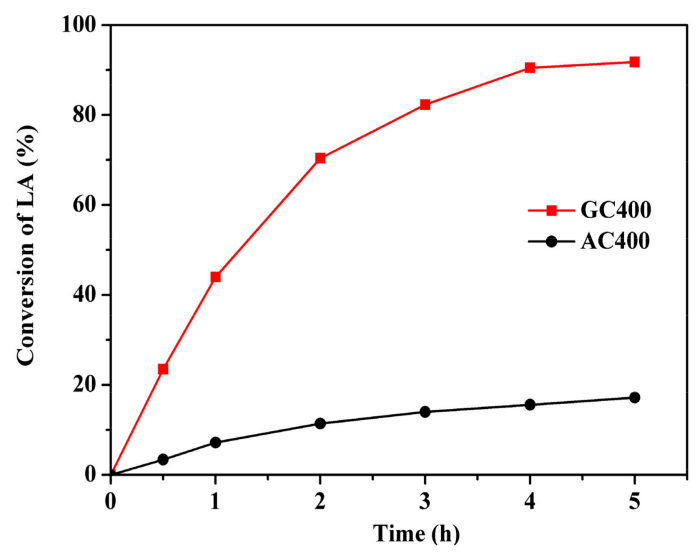

Figure 4. Conversions of LA over two sulfonated carbon materials as the function of reaction time. Reaction conditions: $1.16 \mathrm{~g}$ LA, $3.7 \mathrm{~g}$ n-butanol and $0.116 \mathrm{~g}$ catalyst, $373 \mathrm{~K}, 4 \mathrm{~h}$.

In order to explore the reasons for the distinct activities of two sulfonated carbons, a comparative test was carried out under the catalysis of $\mathrm{H}_{2} \mathrm{SO}_{4}, \mathrm{H}_{3} \mathrm{PO}_{4}$ and $\mathrm{CH}_{3} \mathrm{COOH}$, which represent strong acid, medium acid and weak acid, respectively. The sequence for the conversion of $\mathrm{LA}$ was $\mathrm{H}_{2} \mathrm{SO}_{4}>\mathrm{H}_{3} \mathrm{PO}_{4}$ $>\mathrm{CH}_{3} \mathrm{COOH}$ (see Figure S5), which was consistent with the acid strength of these acids. The result demonstrated that the esterification of LA and n-butanol was sensitive to the acid strength of catalyst. Strong acid was more active than weak acid for this reaction. Moreover, another test was conducted under the catalysis of different concentrations of $\mathrm{H}_{2} \mathrm{SO}_{4}$. The conversion of LA improved significantly with the increasing $\mathrm{H}_{2} \mathrm{SO}_{4}$ concentration from 1 to $20 \mathrm{wt} \%$ (see Figure S6). It further proved the positive effect of $-\mathrm{SO}_{3} \mathrm{H}$ density on esterification. Therefore, combining with the previous characterization results, the excellent catalytic performance of GC400 can be rationalized by its stronger acidity and higher $-\mathrm{SO}_{3} \mathrm{H}$ density. In addition, the swelling capacity of GC400 probably also contributed to the high catalytic performance because it provided good access of the reactants in solution to the $-\mathrm{SO}_{3} \mathrm{H}$ sites in the carbon material. Finally, the catalytic activities of two catalysts were studied with identical amounts of $-\mathrm{SO}_{3} \mathrm{H}$ groups in the reaction system (see Figure S7). Furthermore, 20\% conversion of 
LA on GC400 and $6.2 \%$ conversion of LA on AC400 were obtained after $1.5 \mathrm{~h}$. The activity difference further demonstrated the importance of strong acid strength and good accessibility of acid sites (due to the swelling capacity and abundant oxygenated functional groups) for the excellent activity of GC400.

\subsection{Effect of Reaction Temperature over Two Sulfonated Carbon Materials}

Figure 5 shows the conversion of LA varied with reaction temperature over two sulfonated carbons at n-butanol to LA molar ratio of 5:1 and catalyst loading of $10 \mathrm{wt} \%$. Both catalysts exhibited a growing trend in catalytic activity with the increasing reaction temperature. In general, elevated temperature is conducive to the forward reaction, as esterification reaction is a reversible endothermic process. The optimal reaction temperature was found to be $373 \mathrm{~K}$; at this time, the conversion of LA over GC400 was observed to increase up to $90.5 \%$ from $31.6 \%$ at reaction temperature of $333 \mathrm{~K}$. With a further increment to $393 \mathrm{~K}$, there was no appreciable enhancement in LA conversion. AC400 still demonstrated a poor activity even at elevated temperature of $393 \mathrm{~K}$, and the effect of mass transfer limitation has been excluded (see Figure S8). Therefore, GC400 was selected for the further optimization.

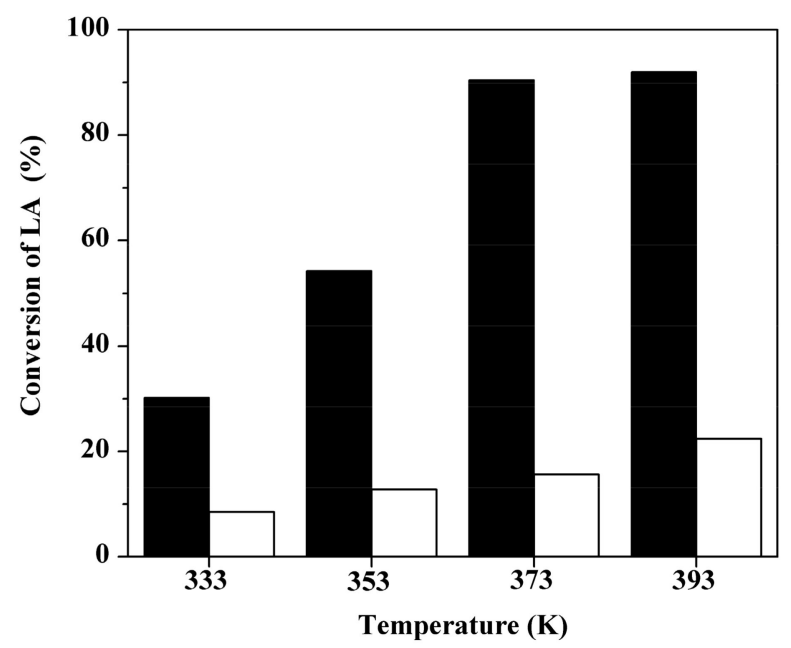

Figure 5. Conversions of LA over GC400 (black) and AC400 (white) at different reaction temperature. Reaction conditions: $1.16 \mathrm{~g}$ LA, $3.7 \mathrm{~g}$ n-butanol and $0.116 \mathrm{~g}$ catalyst, $4 \mathrm{~h}$.

\subsection{Effect of Reactant Molar Ratio and Catalyst Loading over GC400}

The n-butanol to LA molar ratio was varied between 1:1 to 7:1 over GC400 at reaction temperature $373 \mathrm{~K}$, reaction time $4 \mathrm{~h}$ and catalyst loading $10 \mathrm{wt} \%$. As shown in Figure 6a, LA conversion increased gradually from 45.2 to $90.5 \%$ with an increase in n-butanol to LA ratio from 1:1 to 5:1. A further increase in molar ratio did not significantly increase the conversion of LA, and even had a negative effect. Increasing the alcohol amount is an advantage to accelerate the forward reaction, as esterification is reversible. However, excessive dilution in the reaction system may reduce the frequency of collision [38] and flood the active sites of catalyst [39], thereby restricting a further increase in conversion. A similar phenomenon was observed by Maheria et al. [22] in the esterification catalyzed by zeolites. In the present case, the n-butanol to LA molar ratio of 5 was observed to be an optimum.

The effect of catalyst loading on the conversion of LA was also studied at a temperature of $373 \mathrm{~K}$, reaction time of $4 \mathrm{~h}$ and an n-butanol to LA molar ratio of 5:1. The dosage of GC400 catalyst was varied in the range of $2-15 \mathrm{wt} \%$ relative to the weight of LA. Figure $6 \mathrm{~b}$ shows that a higher reaction rate and conversion of LA were observed with an increase in catalyst loading from 2 to $10 \mathrm{wt} \%$, as the number of available sites for the reaction increased. Further heightening the catalyst amount to $15 \mathrm{wt} \%$ made no distinct increment in esterification efficiency. This marginal increase in LA conversion may be due to catalyst agglomeration or decrease in contact opportunities between the reactants. 


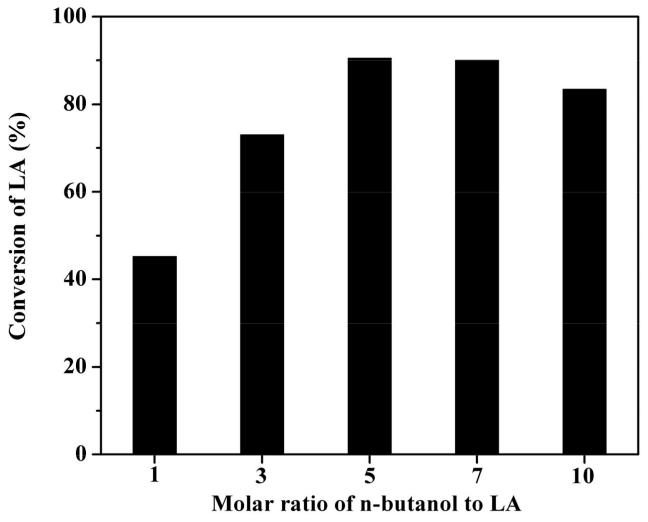

(a)

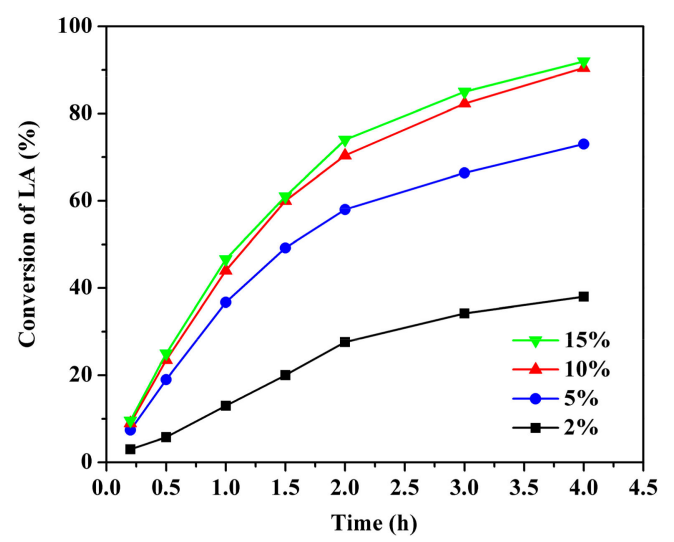

(b)

Figure 6. Conversions of LA over GC400 as the function of molar ratio of n-butanol to LA (a) or as the function of catalyst loading (b). Reaction conditions: (a) $1.16 \mathrm{~g} \mathrm{LA}, 0.116 \mathrm{~g}$ catalyst, $373 \mathrm{~K}, 4 \mathrm{~h}$; (b) $1.16 \mathrm{~g} \mathrm{LA}, 3.7 \mathrm{~g}$ n-butanol, $373 \mathrm{~K}, 4 \mathrm{~h}$.

\subsection{Comparison with Other Typical Solid Acids}

Various typical solid acid catalysts (HZSM-5, H $\beta$ zeolite, Amberlyst-15 and Nafion-212 resin) were chosen to evaluate their catalytic performance under the same reaction conditions. The acid strength, acid densities and activities of various samples were summarized in Table 2. The acid strength was represented by the Hammett acidity function $\left(-\mathrm{H}_{0}\right)$ values of these catalysts. The TOF values were calculated according to the initial LA conversion rate and the $-\mathrm{SO}_{3} \mathrm{H}$ amount. As we can see, the TOF decreased in the order of GC400 > Nafion-212 > Amberlyst-15 > H $\beta>$ HZSM-5. The result agrees with the recent study by Fernandes et al. [13], who found that the activity of zeolites in esterification of LA were generally lower than that of sulfated oxides. The poor activity of zeolites is related to the formation of the transition state inside the channels rather than to their acidity. This may explain the activity gap between $\mathrm{H} \beta$ and HZSM- 5 due to their different pore channels.

Table 2. Hammett acidy function $\left(-\mathrm{H}_{0}\right)$ values, acid density and catalytic activity of the solid acids.

\begin{tabular}{|c|c|c|c|c|c|c|}
\hline Catalyst & $-\mathbf{H}_{0}$ & $\begin{array}{c}-\mathrm{SO}_{3} \mathrm{H} \\
\text { Density } \\
\left(\mathrm{mmol} \cdot \mathrm{g}^{-1}\right)\end{array}$ & $\begin{array}{l}\text { Total Acid } \\
\text { Density }^{a} \\
\left(\mathrm{mmol} \cdot \mathrm{g}^{-1}\right)\end{array}$ & $\begin{array}{c}\text { LA Conversion } \\
(\%)\end{array}$ & TOF $^{c}\left(h^{-1}\right)$ & $\begin{array}{l}\text { Functional } \\
\text { Groups }\end{array}$ \\
\hline HZSM-5 & $5.6 \sim 5.7[40]$ & - & 2.0 & 20.8 & $4.3^{\mathrm{d}}$ & Acidic $-\mathrm{OH}$ \\
\hline $\mathrm{H} \beta$ & $4.4 \sim 5.7[41]$ & - & 1.46 & 33.4 & $7.2^{\mathrm{d}}$ & Acidic $-\mathrm{OH}$ \\
\hline Amberlyst- 15 & $2.2[42]$ & 4.8 & 4.8 & 78.0 & 10.7 & $-\mathrm{SO}_{3} \mathrm{H}$ \\
\hline Nafion-212 & $11 \sim 13[40]$ & 0.9 & 0.9 & 93.3 & 59.0 & $-\mathrm{SO}_{3} \mathrm{H}$ \\
\hline GC400 & $8 \sim 11$ [43] & 0.66 & 1.1 & 90.5 & 95.8 & $\begin{array}{c}-\mathrm{SO}_{3} \mathrm{H},-\mathrm{COOH}, \\
\text { phenolic }-\mathrm{OH}\end{array}$ \\
\hline
\end{tabular}

${ }^{a}$ Determined by $\mathrm{NH}_{3}$-TPD. ${ }^{\mathrm{b}} 1.16 \mathrm{~g} \mathrm{LA}, 3.7 \mathrm{~g} \mathrm{n}$-butanol, $0.116 \mathrm{~g}$ catalyst, $373 \mathrm{~K}, 4 \mathrm{~h} .{ }^{\mathrm{c}}$ Calculated based on the

$-\mathrm{SO}_{3} \mathrm{H}$ density. $1.16 \mathrm{~g} \mathrm{LA}, 3.7 \mathrm{~g}$ n-butanol, $0.058 \mathrm{~g}$ catalyst, $373 \mathrm{~K}, 1 \mathrm{~h}$. ${ }^{\mathrm{d}}$ Calculated based on the total acid density.

Amberlyst- 15 is a polymer-based solid acid with moderate acidity and high $-\mathrm{SO}_{3} \mathrm{H}$ density. $76 \%$ conversion of LA could be obtained on Amberlyst-15, which was lower than that on GC400 with lower $-\mathrm{SO}_{3} \mathrm{H}$ density but stronger acidity. The result furthermore indicates that the esterification of LA and n-butanol was sensitive to the acid strength of catalyst. Nafion-212 resin is a kind of perfluorosulfonic acid-based catalyst, which has a strong Hammett acidity similar to sulfuric acid. It is worth noting that, although Nafion-212 had stronger acidity $\left(-\mathrm{H}_{0}=11-13 \mathrm{vs.} 8-11\right)$ and higher $-\mathrm{SO}_{3} \mathrm{H}$ density $\left(0.9 \mathrm{mmol} \mathrm{g}{ }^{-1}\right.$ vs. $\left.0.66 \mathrm{mmol} \cdot \mathrm{g}^{-1}\right)$ than GC400, the TOF value obtained on Nafion-212 $\left(59.0 \mathrm{~h}^{-1}\right)$ was significantly lower than that obtained on GC400 $\left(95.8 \mathrm{~h}^{-1}\right)$. Therefore, the activity difference could not be simply explained by the acid strength or density. One possible origin of the high efficiency is the specific phenolic - $\mathrm{OH}$ and - $\mathrm{COOH}$ groups on GC400. As Nafion-212 and GC400 
are both non-porous materials with swelling capacity, increasing the accessibility of acid sites in the bulk structure has a strong effect on catalyst activity. Even if phenolic - $\mathrm{OH}$ and $-\mathrm{COOH}$ groups on GC400 contribute little due to their insufficient acidity, they are supposed to increase interaction ability with hydrophilic reactants in solution and provide good access to the $-\mathrm{SO}_{3} \mathrm{H}$ sites. In this case, higher esterification reaction rate was observed on GC400 at the early stage of esterification (see Figure S9). Further detailed study will be necessary to determine how these functional groups contribute to the reaction.

\subsection{Stability Test}

The reusability of GC400 catalyst was investigated under the optimal reaction conditions. The catalyst was recovered, washed and dried before another reaction was conducted. As shown in Figure 7, GC400 was observed to retain a remarkably high proportion (92\%) of its original catalytic activity after five cycles. A hot filtration test was conducted to prove the stability of $-\mathrm{SO}_{3} \mathrm{H}$ groups. By using the reaction mixture filtered at reaction time of $2 \mathrm{~h}$, we run another batch of reaction. No change in LA conversion was noticed after reacting for another $2 \mathrm{~h}$. The result indicated that GC400 catalyst was behaving in a truly heterogeneous manner and no catalytic activity could be attributed to the leached species in the solution. The slight decline in activity after three cycles was due to the catalyst mass being lost in the filtration and washing steps. As GC400 is composed of polycyclic aromatic carbon sheets, the inherent hydrophobicity of carbon can prevent the hydration of $-\mathrm{OH}$ groups. Meanwhile, the electron-withdrawing - $\mathrm{COOH}$ groups in GC400 are supposed to increase the electron density between carbon and sulfur atoms, resulting in the tight attachment of $-\mathrm{SO}_{3} \mathrm{H}$ groups to carbon framework. This might partially explain for the observation that the glucose-derived catalyst was especially robust.

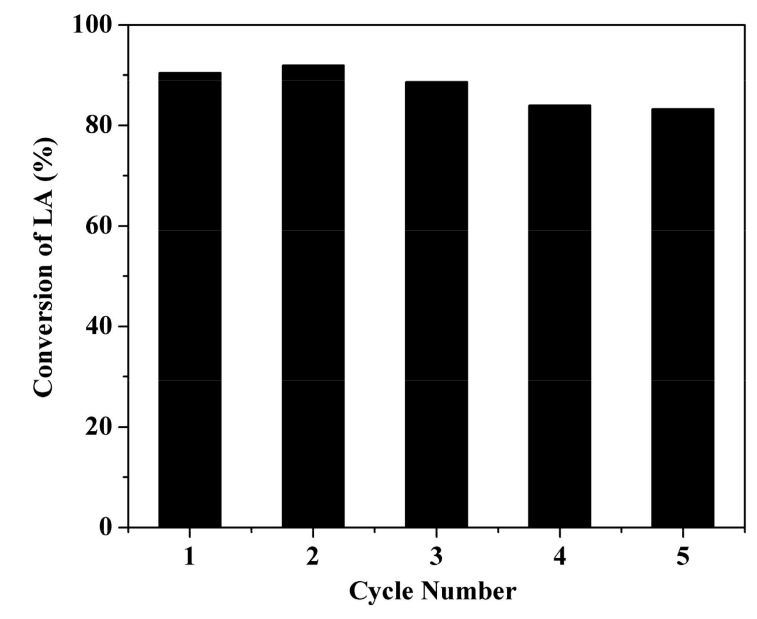

Figure 7. Stability test of GC400. Reaction conditions: $1.16 \mathrm{~g} \mathrm{LA}, 3.7 \mathrm{~g}$ n-butanol, $0.116 \mathrm{~g}$ catalyst, $373 \mathrm{~K}, 4 \mathrm{~h}$.

\subsection{Merits of the Present Method}

According to previous literature, very few reports are available on the esterification of LA with n-butanol. Dharne et al. [21] has claimed that $97 \%$ conversion of LA could be obtained using $\mathrm{H}_{3} \mathrm{PW}_{12} \mathrm{O}_{40} / \mathrm{K} 10$ catalyst in the esterification of LA and n-butanol, but the activity suffered a drastic decrease after the third run due to the leaching of heteropolyacid from supports. Maheria et al. [22] has reported at a higher temperature of $393 \mathrm{~K}$ and a higher n-butanol ratio of 7:1, 82.2\% conversion of LA could be obtained on H-BEA zeolite. It is also reported by Cirujano et al. [24] that LA was almost quantitatively converted to esters on $\mathrm{Zr}$-containing metal-organic frameworks formed by either terephthalate or 2-aminoterephthalate ligands. In addition, Al-modified MCM-41 exhibited 90\% yield of BL after a long reaction time of $8 \mathrm{~h}$ in the esterification of LA with n-butanol, and the calcination step was inevitable to keep its activity during each cycle [25]. As for immobilized lipase catalysts, 
despite them being active, solvent washing after each run led to difficulties in operation [29]. As we can see, comparing with those reported solid acids, sulfonated glucose-derived carbon possesses great advantages with respect to operation cost, catalytic activity and reusability.

\section{Materials and Methods}

\subsection{Catalyst Preparation}

Sulfonated glucose-derived carbon (denoted as GC400) was prepared according to Hara's method [23] with minor modifications. All the chemicals were purchased from Sinopharm Chemcial Reagent Company (Beijing, China). 1 g glucose powder was heated for $12 \mathrm{~h}$ at $673 \mathrm{~K}$ under $\mathrm{N}_{2}$ flow to produce a brown-black solid. The solid was grounded to powder and heated in $10 \mathrm{~cm}^{3}$ of concentrated $\mathrm{H}_{2} \mathrm{SO}_{4}$ at $423 \mathrm{~K}$ for one day. The black precipitate was washed thoroughly with hot distilled water until no sulfate ions were detected in the filtrate. The prepared catalyst was dried at $373 \mathrm{~K}$ in a vacuum oven. The particle size of GC400 was around 5 20 $\mu \mathrm{m}$ (see Figure S10). Sulfonated active carbon (denoted as AC400) was prepared by sulfonating grinded active carbon (coconut shell carbon, NORIT Company, Boston, MA, USA) in concentrated $\mathrm{H}_{2} \mathrm{SO}_{4}$ at $423 \mathrm{~K}$ for one day. $\mathrm{HZSM}-5\left(\mathrm{SiO}_{2} / \mathrm{Al}_{2} \mathrm{O}_{3}=25\right)$ and $\mathrm{H} \beta$ $\left(\mathrm{SiO}_{2} / \mathrm{Al}_{2} \mathrm{O}_{3}=25\right)$ zeolites were provided by Nankai University. Nafion-212 resin was purchased from Dupont. Amberlyst-15 resin was purchased from Sigma-Aldrich (St. Louis, MO, USA).

\subsection{Catalyst Characterization}

The specific surface areas $\left(\mathrm{S}_{\mathrm{BET}}\right)$ of the catalysts were measured by $\mathrm{N}_{2}$ adsorption, which was carried out at $77 \mathrm{~K}$ using an ASAP 2010 apparatus (Micromeritics, Norcross, GA, USA). Before each measurement, the sample was evacuated at $573 \mathrm{~K}$ for $3 \mathrm{~h}$. The structure of the catalyst was characterized by with a PANalytical X'Pert-Pro X-ray diffractometer (Bruker, Karlsruhe, Germany), using Cu K $\alpha$ monochromatized radiation $(\lambda=0.1541 \mathrm{~nm})$ at a scan speed of $5^{\circ} \mathrm{min}^{-1}$. Elemental composition of the prepared catalysts was determined by elemental analysis (EA) using an Elementar vario EL $b$ apparatus (Langenselbold, Germany). HRTEM images were collected on an electron microscope (JEM-2100F, JEOL, Tokyo, Japan), using a $200 \mathrm{kV}$ accelerating voltage. FT-IR spectra were recorded by a VERTEX 70 (Bruker, Karlsruhe, Germany) with the KBr pellet ranging from 500 to $4000 \mathrm{~cm}^{-1}$. The acid strength of carbon materials was characterized by $\mathrm{NH}_{3}-\mathrm{TPD}$, which was carried out with a Micromeritics AutoChem II 2920 Automated Catalyst Characterization System (Micromeritics, Norcross, GA, USA) coupling with a mass spectrometry (MS) detector (Pfeiffer Vacuum, Nashua, NH, USA). The detailed procedure has been described in our previous works [44]. Before each test, $0.1 \mathrm{~g}$ sample was placed in a quartz reactor, pretreated in He flow at $393 \mathrm{~K}$ for $1 \mathrm{~h}$ and cooled down in Helium flow to $373 \mathrm{~K}$. After the saturated adsorption $\mathrm{NH}_{3}$, the sample was heated at $373 \mathrm{~K}$ in $\mathrm{He}$ for $30 \mathrm{~min}$ to remove the physically adsorbed $\mathrm{NH}_{3}$. Desorption of $\mathrm{NH}_{3}$ was conducted in He flow from $373 \mathrm{~K}$ to $1073 \mathrm{~K}$ at a heating rate of $10 \mathrm{~K} \mathrm{~min}^{-1}$. The desorbed $\mathrm{NH}_{3}$ molecules were detected by a MS OminiStar (Pfeiffer Vacuum, Nashua, NH, USA) equipped with the software quadstar 32-bit (Pfeiffer Vacuum, Nashua, $\mathrm{NH}, \mathrm{USA})$.

\subsection{Esterification of LA and N-Butanol}

Esterification reaction was carried out in a Parr batch reactor (Parr, Moline, IL, USA). Typically, $1.16 \mathrm{~g}(0.01 \mathrm{~mol}) \mathrm{LA}, 3.7 \mathrm{~g}(0.05 \mathrm{~mol}) \mathrm{n}$-butanol and $0.116 \mathrm{~g}$ catalyst were put into the reactor. The mixture was stirred at $373 \mathrm{~K}$ for $4 \mathrm{~h}$ with stirrer speed of $200 \mathrm{rpm}$. The liquid product was filtered and analyzed by an Agilent 1100 HPLC (Santa Clara, CA, USA) equipped with a ZORBAX SB-C18 $(4.6 \times 150 \mathrm{~mm}, 5 \mathrm{~mm})$ column (Santa Clara, CA, USA) and refractive index detector (RID). The solution of methanol and water $(7: 3 v / v)$ was used as the eluent. The LA conversion was calculated by its consumption. The reusability of glucose-derived carbon was investigated under the optimal reaction conditions. After each cycle of use, the catalyst was filtered, thoroughly washed with acetone, 
and vacuum dried at $373 \mathrm{~K}$ before another batch reaction. All the chemicals were purchased from Sinopharm Chemcial Reagent Company (Beijing, China).

\section{Conclusions}

$\mathrm{N}$-butyl levulinate fuel additive was successfully synthesized through the esterification of LA and n-butanol over a sulfonated carbon (GC400) bearing $-\mathrm{SO}_{3} \mathrm{H},-\mathrm{COOH}$ and phenolic $-\mathrm{OH}$ groups. Compared with the commercial active carbon, the amorphous carbon prepared from incomplete carbonization of glucose possessed smaller carbon sheets that were easier to be sulfonated, resulting in higher $-\mathrm{SO}_{3} \mathrm{H}$ density of GC400. The unique swelling capacity of GC400 could provide good access of reactants to the $-\mathrm{SO}_{3} \mathrm{H}$ sites located in the carbon matrix, despite the small surface area. Under the optimized conditions ( $373 \mathrm{~K}, 4 \mathrm{~h}$, n-butanol to LA molar ratio of 5:1, catalyst loading of $10 \%$ ), GC400 displayed a much higher catalytic efficiency than sulfonated active carbon, HZSM-5 and Nafion-212 for esterification. The strong acid strength and high $-\mathrm{SO}_{3} \mathrm{H}$ density, probably in cooperation with weak acid sites $(-\mathrm{COOH}$ and phenolic $-\mathrm{OH})$ attached on the carbon surface, are the main factors for its excellence.

Supplementary Materials: The following are available online at www.mdpi.com/2073-4344/8/1/14/s1, Figure S1: HRTEM images of GC400 (a) and AC400 (b), Figure S2: The behavior of GC400 (a) and AC400 (b) in contact with n-butanol, Figure S3: $\mathrm{NH}_{3}$-TPD results of GC400 and unsulfonated GC400, Figure S4: HPLC chromatograms of the liquid products from the esterification of LA and n-butanol over GC400 (a) and AC400 (b), Figure S5: Conversions of LA catalyzed by different liquid acids, Figure S6: Conversions of LA catalyzed by different concentrations of $\mathrm{H}_{2} \mathrm{SO}_{4}$ solution, Figure S7: Conversions of LA over GC400 and AC400 when identical amounts of $-\mathrm{SO}_{3} \mathrm{H}$ sites in reaction mixture were utilized, Figure S8: Effect of stirrer speed (a) and particle size (b) on esterification of LA over AC400. Figure S9: Conversions of LA over GC400 and Nafion-212 as the function of reaction time, Figure S10: SEM images of GC400 sample, Table S1: Acid amount of different functional groups on two samples.

Acknowledgments: This work was supported by the Natural Science Foundation Research Project of Shaanxi Province (No. 2017JQ2015), and the Scientific Research Foundation of Shaanxi University of Science and Technology (No. 2015BJ-27).

Author Contributions: Jinfan Yang conceived and designed the experiments; Guangyi Li and Lulu Zhang performed the experiments; Jinfan Yang analyzed the data; Sufeng Zhang contributed reagents and analysis tools; and Jinfan Yang wrote the paper.

Conflicts of Interest: The authors declare no conflict of interest.

\section{References}

1. Huber, G.W.; Iborra, S.; Corma, A. Synthesis of transportation fuels from biomass: Chemistry, catalysts, and engineering. Chem. Rev. 2006, 106, 4044-4098. [CrossRef] [PubMed]

2. Alonso, D.M.; Bond, J.Q.; Dumesic, J.A. Catalytic conversion of biomass to biofuels. Green Chem. 2010, 12, 1493-1513. [CrossRef]

3. Climent, M.J.; Corma, A.; Iborra, S. Conversion of biomass platform molecules into fuel additives and liquid hydrocarbon fuels. Green Chem. 2014, 16, 516-547. [CrossRef]

4. Corma, A.; Iborra, S.; Velty, A. Chemical routes for the transformation of biomass into chemicals. Chem. Rev. 2007, 107, 2411-2502. [CrossRef] [PubMed]

5. Mascal, M.; Nikitin, E.B. High-yield conversion of plant biomass into the key value-added feedstocks 5-(hydroxymethyl)furfural, levulinic acid, and levulinic esters via 5-(chloromethyl)furfural. Green Chem. 2010, 12, 370-373. [CrossRef]

6. Bozell, J.J.; Petersen, G.R. Technology development for the production of biobased products from biorefinery carbohydrates-The US department of energy's "top 10" revisited. Green Chem. 2010, 12, 539-554. [CrossRef]

7. Antonetti, C.; Licursi, D.; Fulignati, S.; Valentini, G.; Raspolli Galletti, A. New frontiers in the catalytic synthesis of levulinic acid: From sugars to raw and waste biomass as starting feedstock. Catalysts 2016, 6, 196. [CrossRef]

8. Hayes, D.J. An examination of biorefining processes, catalysts and challenges. Catal. Lett. 2009, 145, 138-151. [CrossRef] 
9. Nandiwale, K.Y.; Sonar, S.K.; Niphadkar, P.S.; Joshi, P.N.; Deshpande, S.S.; Patil, V.S.; Bokade, V.V. Catalytic upgrading of renewable levulinic acid to ethyl levulinate biodiesel using dodecatungstophosphoric acid supported on desilicated H-ZSM-5 as catalyst. Appl. Catal. A Gen. 2013, 460-461, 90-98. [CrossRef]

10. Yan, K.; Wu, G.; Wen, J.; Chen, A. One-step synthesis of mesoporous $\mathrm{H}_{4} \mathrm{SiW}_{12} \mathrm{O}_{40}-\mathrm{SiO}_{2}$ catalysts for the production of methyl and ethyl levulinate biodiesel. Catal. Commun. 2013, 34, 58-63. [CrossRef]

11. Nandiwale, K.Y.; Niphadkar, P.S.; Deshpande, S.S.; Bokade, V.V. Esterification of renewable levulinic acid to ethyl levulinate biodiesel catalyzed by highly active and reusable desilicated H-ZSM-5. J. Chem. Technol. Biotechnol. 2014, 89, 1507-1515. [CrossRef]

12. Patil, C.R.; Niphadkar, P.S.; Bokade, V.V.; Joshi, P.N. Esterification of levulinic acid to ethyl levulinate over bimodal micro-mesoporous H/BEA zeolite derivatives. Catal. Commun. 2014, 43, 188-191. [CrossRef]

13. Fernandes, D.R.; Rocha, A.S.; Mai, E.F.; Mota, C.J.A.; Teixeira da Silva, V. Levulinic acid esterification with ethanol to ethyl levulinate production over solid acid catalysts. Appl. Catal. A Gen. 2012, 425-426, 199-204. [CrossRef]

14. Osatiashtiani, A.; Durndell, L.J.; Manayil, J.C.; Lee, A.F.; Wilson, K. Influence of alkyl chain length on sulfated zirconia catalysed batch and continuous esterification of carboxylic acids by light alcohols. Green Chem. 2016, 18, 5529-5535. [CrossRef]

15. Oliveira, B.L.; Teixeira da Silva, V. Sulfonated carbon nanotubes as catalysts for the conversion of levulinic acid into ethyl levulinate. Catal. Today 2014, 234, 257-263. [CrossRef]

16. Budarin, V.L.; Clark, J.H.; Luque, R.; Macquarrie, D.J. Versatile mesoporous carbonaceous materials for acid catalysis. Chem. Commun. 2007, 634-636. [CrossRef] [PubMed]

17. Su, F.; Ma, L.; Song, D.; Zhang, X.; Guo, Y. Design of a highly ordered mesoporous $\mathrm{H}_{3} \mathrm{PW}_{12} \mathrm{O}_{40} / \mathrm{ZrO}_{2}-\mathrm{Si}(\mathrm{Ph}) \mathrm{Si}$ hybrid catalyst for methyl levulinate synthesis. Green Chem. 2013, 15, 885-890. [CrossRef]

18. Christensen, E.; Yanowitz, J.; Ratcliff, M.; McCormick, R.L. Renewable oxygenate blending effects on gasoline properties. Energy Fuels 2011, 25, 4723-4733. [CrossRef]

19. Shrivastav, G.; Khan, T.S.; Agarwal, M.; Haider, M.A. Reformulation of gasoline to replace aromatics by biomass-derived alkyl levulinates. ACS Sustain. Chem. Eng. 2017, 5, 7118-7127. [CrossRef]

20. Earl Christensen, A.W.; Paul, S.; Burton, S.; McCormick, A.R.L. Properties and performance of levulinate esters as diesel blend components. Energy Fuels 2011, 25, 5422-5428. [CrossRef]

21. Dharne, S.; Bokade, V.V. Esterification of levulinic acid to n-butyl levulinate over heteropolyacid supported on acid-treated clay. J. Nat. Gas Chem. 2011, 20, 18-24. [CrossRef]

22. Maheria, K.C.; Kozinski, J.; Dalai, A. Esterification of levulinic acid to n-butyl levulinate over various acidic zeolites. Catal. Lett. 2013, 143, 1220-1225. [CrossRef]

23. Nandiwale, K.Y.; Bokade, V.V. Esterification of renewable levulinic acid to n-butyl levulinate over modified h-zsm-5. Chem. Eng. Technol. 2015, 38, 246-252. [CrossRef]

24. Cirujano, F.G.; Corma, A.; Llabrés i Xamena, F.X. Conversion of levulinic acid into chemicals: Synthesis of biomass derived levulinate esters over Zr-containing MOFs. Chem. Eng. Sci. 2015, 124, 52-60. [CrossRef]

25. Najafi Chermahini, A.; Nazeri, M. Esterification of the levulinic acid with n-butyl and isobutyl alcohols over aluminum-containing MCM-41. Fuel Process. Technol. 2017, 167, 442-450. [CrossRef]

26. Tejero, M.A.; Ramírez, E.; Fité, C.; Tejero, J.; Cunill, F. Esterification of levulinic acid with butanol over ion exchange resins. Appl. Catal. A Gen. 2016, 517, 56-66. [CrossRef]

27. Trombettoni, V.; Bianchi, L.; Zupanic, A.; Porciello, A.; Cuomo, M.; Piermatti, O.; Marrocchi, A.; Vaccaro, L. Efficient catalytic upgrading of levulinic acid into alkyl levulinates by resin-supported acids and flow reactors. Catalysts 2017, 7, 235. [CrossRef]

28. Nakhate, A.V.; Yadav, G.D. Synthesis and characterization of sulfonated carbon-based graphene oxide monolith by solvothermal carbonization for esterification and unsymmetrical ether formation. ACS Sustain. Chem. Eng. 2016, 4, 1963-1973. [CrossRef]

29. Badgujar, K.C.; Bhanage, B.M. Thermo-chemical energy assessment for production of energy-rich fuel additive compounds by using levulinic acid and immobilized lipase. Fuel Process. Technol. 2015, 138, 139-146. [CrossRef]

30. Toda, M.; Takagaki, A.; Okamura, M.; Kondo, J.N.; Hayashi, S.; Domen, K.; Hara, M. Green chemistry: Biodiesel made with sugar catalyst. Nature 2005, 438, 178. [CrossRef] [PubMed] 
31. Okamura, M.; Takagaki, A.; Toda, M.; Kondo, J.N.; Domen, K.; Tatsumi, T.; Hara, M.; Hayashi, S. Acid-catalyzed reactions on flexible polycyclic aromatic carbon in amorphous carbon. Chem. Mater. 2006, 18, 3039-3045. [CrossRef]

32. Lou, W.; Zong, M.; Duan, Z. Efficient production of biodiesel from high free fatty acid-containing waste oils using various carbohydrate-derived solid acid catalysts. Bioresour. Technol. 2008, 99, 8752-8758. [CrossRef] [PubMed]

33. Lokman, I.M.; Rashid, U.; Taufiqyap, Y.H.; Yunus, R. Methyl ester production from palm fatty acid distillate using sulfonated glucose-derived acid catalyst. Renew. Energy 2015, 81, 347-354. [CrossRef]

34. Cao, X.; Sun, S.; Sun, R. Application of biochar-based catalysts in biomass upgrading: A review. RSC Adv. 2017, 7, 48793-48805. [CrossRef]

35. Dandekar, A.; Baker, R.T.K.; Vannice, M.A. Characterization of activated carbon, graphitized carbon fibers and synthetic diamond powder using TPD and drifts. Carbon 1998, 36, 1821-1831. [CrossRef]

36. Chen, G.; Fang, B. Preparation of solid acid catalyst from glucose-starch mixture for biodiesel production. Bioresour. Technol. 2011, 102, 2635-2640. [CrossRef] [PubMed]

37. Dawodu, F.A.; Ayodele, O.; Xin, J.; Zhang, S.; Yan, D. Effective conversion of non-edible oil with high free fatty acid into biodiesel by sulphonated carbon catalyst. Appl. Energy 2014, 114, 819-826. [CrossRef]

38. Shu, Q.; Gao, J.; Nawaz, Z.; Liao, Y.; Wang, D.; Wang, J. Synthesis of biodiesel from waste vegetable oil with large amounts of free fatty acids using a carbon-based solid acid catalyst. Appl. Energy 2010, 87, 2589-2596. [CrossRef]

39. Zhou, Y.; Niu, S.; Li, J. Activity of the carbon-based heterogeneous acid catalyst derived from bamboo in esterification of oleic acid with ethanol. Energy Convers. Manag. 2016, 114, 188-196. [CrossRef]

40. Okuhara, T. Water-tolerant solid acid catalysts. Chem. Rev. 2002, 102, 3641-3666. [CrossRef] [PubMed]

41. Cadenas, M.; Bringué, R.; Fité, C.; Ramírez, E.; Cunill, F. Liquid-Phase Oligomerization of 1-Hexene Catalyzed by Macroporous Ion-Exchange Resins. Top. Catal. 2011, 54, 998-1008. [CrossRef]

42. Suganuma, S.; Nakajima, K.; Kitano, M.; Yamaguchi, D.; Kato, H.; Hayashi, S. Hydrolysis of cellulose by amorphous carbon bearing $\mathrm{SO}_{3} \mathrm{H}, \mathrm{COOH}$, and $\mathrm{OH}$ groups. J. Am. Chem. Soc. 2008, 130, 12787-12793. [CrossRef] [PubMed]

43. Takagaki, A.; Toda, M.; Okamura, M.; Kondo, J.N.; Hayashi, S.; Domen, K.; Hara, M. Esterification of higher fatty acids by a novel strong solid acid. Catal. Today 2006, 116, 157-161. [CrossRef]

44. Yang, J.; Li, N.; Li, S.; Wang, W.; Li, L.; Wang, A.; Wang, X.; Cong, Y.; Zhang, T. Synthesis of diesel and jet fuel range alkanes with furfural and ketones from lignocellulose under solvent free conditions. Green Chem. 2014, 16, 4879-4884. [CrossRef] 